\title{
The use of food swaps to encourage healthier online food choices: a randomized controlled trial
}

\author{
Laura Jansen (1), Ellen van Kleef(D) and Ellen J. Van Loo * (10)
}

\begin{abstract}
Background: Online grocery stores offer opportunities to encourage healthier food choices at the moment that consumers place a product of their choice in their basket. This study assessed the effect of a swap offer, Nutri-Score labeling, and a descriptive norm message on the nutrient profiling (NP) score of food choices in an online food basket. Additionally explored was whether these interventions made it more motivating and easier for consumers to select healthier foods and whether potential effects were moderated by consumer health interest.

Methods: Hypotheses were tested with a randomized controlled trial (RCT) in a simulated online supermarket. Dutch participants $(n=550)$ chose their preferred product out of six product options for four different categories (breakfast cereals, crackers, pizza, and muesli bars). Participants were randomly allocated to one of eight groups based on the interventions in a 2 (Nutri-Score: present, not present) X 2 (swap offer: present, not present) X 2 (norm message: present, not present) between subject design. The primary outcome was the difference in combined NP score of product choices, for which a lower score represented a healthier product.
\end{abstract}

Results: Swap offer $\left(B=-9.58,95 \% \mathrm{Cl}\right.$ : $\left.[-12.026 ;-7.132], \eta^{2}=0.098\right)$ and Nutri-Score labeling $(B=-3.28,95 \% \mathrm{Cl}$ : $\left.[-5.724 ;-.829], \eta^{2}=0.013\right)$ significantly improved the combined NP score compared to the control condition (NP score $M=18.03, S D=14.02)$, whereas a norm message did not have a significant effect $(B=-1.378,95 \% \mathrm{Cl}[-3.825$; $1.070], \eta^{2}=0.002$ ). No evidence was found that interventions made it more motivating or easier for consumers to select healthier food, but situational motivation significantly influenced the healthiness score of food choices for both swap offer $(b=-3.40, p<.001)$ and Nutri-Score $(b=-3.25, p<.001)$. Consumer health interest only significantly moderated the influence of Nutri-Score on ease of identifying the healthy food option $(b=.23, p=.04)$.

Conclusions: Swap offer and Nutri-Score labeling were effective in enhancing healthy purchase behavior in the online store environment.

Trial registration: This study was retrospectively registered in the ISRCTN database on 02-09-2021 (ISRCTN8051 9674).

Keywords: Swap offer, Nutri-Score, Descriptive norm message, Situational motivation, Healthy food choices

*Correspondence: ellen.vanloo@wur.nl

Marketing and Consumer Behaviour Group, Wageningen University \&

Research, Hollandseweg 1, 6706 KN Wageningen, the Netherlands

\section{Introduction}

Digital interventions to promote healthier food choices in the online environment have attracted a lot of interest recently [1]. An important way to encourage consumers to consider other options in an online choice environment is through the use of a digital recommender system original author(s) and the source, provide a link to the Creative Commons licence, and indicate if changes were made. The images or other third party material in this article are included in the article's Creative Commons licence, unless indicated otherwise in a credit line to the material. If material is not included in the article's Creative Commons licence and your intended use is not permitted by statutory regulation or exceeds the permitted use, you will need to obtain permission directly from the copyright holder. To view a copy of this licence, visit http://creativecommons.org/licenses/by/4.0/. The Creative Commons Public Domain Dedication waiver (http://creativeco mmons.org/publicdomain/zero/1.0/) applies to the data made available in this article, unless otherwise stated in a credit line to the data. 
[2]. A digital recommender system offering consumers the possibility to swap their initial food choices with similar product alternatives - called a swap offer - has been used to encourage consumers to make healthier food choices $[3,4]$. Examples of food swaps aiming at healthier food purchases are a swap product lower in salt $[3,5]$, energy density [6], or saturated fat [7,8]. Such interventions have proven to successfully change food-purchasing behavior in both physical (e.g. $[4,9,10])$ and online environments (e.g. [3, 4, 7]), as they can help people in expending their competencies of choosing healthy food by asking them to think about the risk of their unhealthy choice in a transparent and understandable form [11].

The use of nutrition labels is a common way to help consumers evaluate the healthfulness of products. Frontof-pack (FOP) nutrition labels are used to provide information to consumers in more understandable formats to encourage healthy consumption [12]. A variety of FOP nutrition labels have emerged, of which Nutri-Score labeling is found to be one of the most promising labeling systems to help consumers identify and rank nutritonal quality of food [13-15]. Nutri-Score is "a graphic scale that divides the nutritional score into five classes (expressed by a color and a letter), the purpose being to help the consumer better see, interpret and understand the nutritional quality" ([16], p.24]). It is a summary indicator label, meaning that it gives an overall rating of product healthfulness [12]. Nutri-Score was developed by Santé Publique France [16] and has been implemented in several countries such as France, Belgium, Spain, the Netherlands, and Germany, and is also likely to be implemented in other countries in the near future to inform consumers about the healthfulness of products [17, 18]. What little research has performed on Nutri-Score showed a positive significant effect of Nutri-Score on understanding nutritional quality of purchases (e.g., [1820]). However, previous research mainly showed only small improvements in the nutritional quality of real-life supermarket food purchases [21] and opted to combine Nutri-Score labels with other interventions, such as educational leaflets, to improve the effectiveness of NutriScore [22].

Aside from providing tools to consumers to make healthy food choices, it is also expected that a descriptive norm message, which is a norm about what the majority of people do [23], can guide consumers toward healthier choices. Social norms are considered one of the most effective ways to nudge people toward a certain behavior [24] and have proven to successfully promote healthy eating behavior (e.g., $[25,26])$. Socials norm messages are effective because people want to obtain social approval from others and be judged positively [25, 27]. The current study explores the effect of providing a swap offer,
Nutri-Score label, or descriptive norm message on the nutrient profiling (NP) score of food choices, for which a better (lower) NP score is expected (hypothesis 1). Additionally, the combined effect of all three strategies seems fruitful to investigate, as they may strengthen each other.

Additionally, we explore whether ease of identifying the healthy food option and situational motivation to choose healthily are mediators between the effect of swap offers, Nutri-Score labelling, and norm message on NP score. For ease of identification, a swap offer is expected to have a positive effect because it increases the visibility of a healthy product (hypothesis 2). Consumers receive feedback that the chosen product is not the healthiest option and are offered a healthier alternative instead. Regarding Nutri-Score, nutrition labels that are easier to interpret seem to have an effect on the ability to identify healthier food choices due to the simplicity of the color and grading system (hypothesis 4) [19, 28-30]. Clear and precise labeling is preferred over ambiguous statements because it increases consumers' perceived control and ability to choose or reject a certain product [31].

For the mediator situational motivation, which is defined as motivation experienced during a particular activity [32], the shopping task, swap offer, Nutri-Score label, and norm message are expected to increase situational motivation because presence of the interventions increases involvement with the product [33]. Being presented with a healthier alternative makes consumers aware of the (un)healthfulness of their food choice which subsequently may motivate them to behave more healthily (hypothesis 3) [34]. Additionally, presence of and attention to the Nutri-Score label make healthfulness information more salient, which may remind consumers about healthy eating and thus motivate them to make a healthy choice in this particular shopping situation (hypothesis 5) [34]. Descriptive social norms have the ability to influence behavior because people want to follow others' behavior to behave efficiently [23]. The logic of "if everyone is doing it, it must be a sensible thing to do" [35, p.1015] serves as a time- and effort-saving shortcut that leads to a certain behavior. Hence, a message with a descriptive norm referring to what peer groups often do can motivate consumers to choose the healthier food option (hypothesis 6) (e.g., [36, 37]).

The proposed mediators are expected to have a positive effect on the NP score of food choices. Situational motivation leads to more healthful choices (hypothesis 7), because motivated people are more likely to invest effort in understanding provided product information and to make product choices accordingly [38, 39]. This means that people with high motivation are more likely to process provided information at product selection (i.e., Nutri-Score, swap offer or descriptive norm message) 
that guides consumers to healthier food choices. Additionally, healthfulness of choices is influenced by the ease of identifying the healthy food option (hypothesis 8). This because ease of identifying the healthy food options due to interventions such as Nutri-Score and swap offer increases the confidence of a person that (s)he can choose healthily, which leads to performing and maintaining healthy behavior [40]. Moreover, it is suggested that situational motivation moderates the effect of ease of identification on healthfulness of food choices (hypothesis 9) because the ability to perform a behavior most likely leads to performance only if the consumers also feel motivated [41]. In addition, people with high motivation and high ability are more likely to use all available product information for decision-making, whereas people with high ability but low motivation do not [39].

Finally, it is proposed that the effect of swap offer, Nutri-Score labeling, and norm message on ease of identification (hypothesis 10) and situational motivation (hypothesis 11) may depend on the consumers' health interest. Interest to engage in health-related behavior can influence the willingness to process healthfulness information and therefore increase the positive effect of interventions [42,43]. Additionally, if a person is highly interested in health-related behavior, an intervention leads to even more motivation than for those with low health interests because of the personal involvement [44, 45].

Hence, the main aim of this study is to investigate the effect of swap offer, Nutri-Score labeling, and norm message in an online store environment in order to evaluate whether these strategies can guide consumers toward healthier food choices. Additionally, we explore whether these interventions increase the ease of identifying healthier foods as well as the situational motivation to choose healthily, which is the motivation to choose in the here and now. Finally, we examine whether potential effects are moderated by consumers' health interest. Hypotheses are presented in Fig. 1. Reporting is performed using the CONSORT checklist (Additional file 1), and a TIDier checklist for the interventions is provided (Additional file 2).

\section{Methods \\ Study design \\ Study design}

To test the hypotheses, a randomized controlled trial (RCT) was conducted in a simulated online supermarket where participants were evenly allocated to eight conditions in a 2 (swap offer: yes versus no) $\times 2$ (Nutri-Score: yes versus no) $\times 2$ (descriptive norm message: yes versus no) between subject design. At a simulated point of purchase of an online supermarket, each respondent individually was exposed to one of the eight conditions where swap offer, Nutri-Score label, and a descriptive norm message were present or not (Table 1).

\section{The products in the simulated online supermarket}

Within the Qualtrics survey, participants were shown a product assortment of four different product categories: breakfast cereals, muesli bars, crackers, and pizza (Additional file 3). Each product category consisted of six

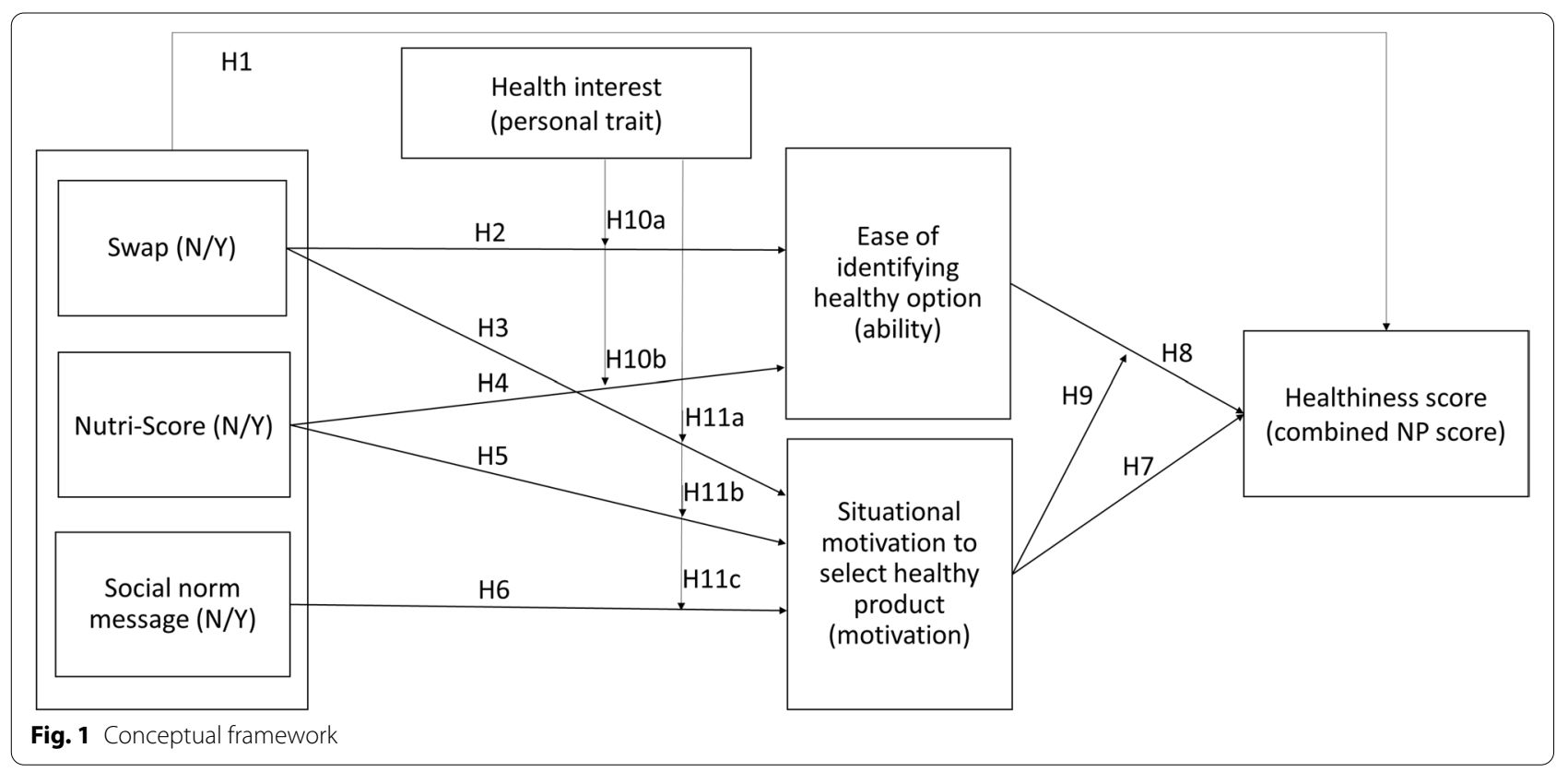


Table 1 Overview of treatment conditions

\begin{tabular}{llll}
\hline Treatment & Nutri-Score & Swap offer & Norm message \\
\hline 1: Control (no intervention) & No & No & No \\
2: Nutri-Score & Yes & No & No \\
3: Norm message & No & No & Yes \\
4: Swap offer & No & Yes & No \\
5: Nutri-Score+ norm & Yes & No & Yes \\
message & & & \\
6: Nutri-Score+ swap offer & Yes & Yes & No \\
7: Norm message + swap & No & Yes & Yes \\
offer & & & \\
8: Nutri-Score+ norm mes- & Yes & Yes & Yes \\
sage + swap offer & & & \\
\hline
\end{tabular}

products with different NP score levels based on NutriScore. Participants were exposed to one of the four product categories at a time and were asked to indicate their choice. Both order of product categories and of the products within one assortment were randomized to prevent order bias. Brand and price information were deleted from all product images to prevent an effect from brand and/or price. An overview of the product assortment for each of the four categories is given in Additional file 3.

\section{Nutri-score intervention}

The effect of Nutri-Score was tested by displaying a Nutri-Score label alongside products in intervention conditions. Nutri-Score label was based on the nutrient profiling (NP) system of the UK Food Standards Agency [46], which uses a scoring system to determine nutrient content per $100 \mathrm{~g}$ of food or drinks [13]. To calculate Nutri-Score, positive and negative points are given to components of the food product. The final Nutri-Score is calculated by subtracting the total number of advantageous points from the total number of disadvantageous points. This way, a score between -15 (healthy) and +40 (unhealthy) is calculated. The healthiest choice is visualized with an A (dark green), and the lowest nutritional value is indicated with an $\mathrm{E}$ (red). For the calculation of the NP scores and the corresponding Nutri-Score, the method by Santé Publique France [16] was followed. An overview of NP scores of the used products, and its calculation is given in Additional file 4. The label was placed on the right side of product images in accordance with the online store environment of Delhaize [47]. An example of a question with a Nutri-Score label is given in Additional file 5.

\section{Swap offer intervention}

If the original chosen product was not the healthiest option in the assortment, a swap offer was provided with a healthier alternative. The product with the lowest NP score for each category was identified as the healthier alternative and used as a swap offer (see Additional file 3). If participants already chose the healthiest option, no swap was offered. In swap interventions with the NutriScore and/or the descriptive norm, the swap offer was displayed with the Nutri-Score label and/or a descriptive norm message (see Additional file 5), respectively.

\section{Descriptive norm message intervention}

The following descriptive norm was developed for the current study: "Dutch consumers more often choose healthy products." This norm was based on results from the Dutch National Institute for Public Health and the Environment (RIVM) [48] showing that more and more Dutch consumers eat healthier. To increase the salience of the norm $[23,49]$, the text was presented in a green banner above the product options (see Additional file 5).

\section{Exposure in each treatment group}

Participants were exposed to one of the eight conditions (Additional file 6), and all participants were exposed to the same products (Additional file 3). Based on their treatment group (Additional file 6), the Nutri-Score, swap offer, and/or norm message were presented. Examples of product choices for each intervention condition are provided in Additional file 5.

\section{Participants}

Participants were recruited by a market agency using a representative sample for the Netherlands in terms of age and gender (age and gender breakdowns from CBS [50]). Participants were eligible if they lived in the Netherlands, were older than 18 , were able to read Dutch, and were willing to provide information. The survey language was Dutch. The required sample size was calculated with a power of 0.8 and an alpha of 0.05 (G*Power version 3.1.9.4) to detect a small effect size (partial $\eta 2=0.04$ with corresponding effect size $f=0.2$ ). This power analysis was performed for our primary hypothesis 1 , meaning that the other hypotheses in our framework were explored without further analysis for power calculation. Based on this calculation, a total sample size of 472 participants was required. A final sample size of 550 participants was set to oversample each condition with approximately 10 participants. As such, the trial ended after 550 participants completed the full survey. In total, 647 people participated, of which 550 completed the full survey in May 2020. There was only one dropout in this study (allocated to Nutri-Score with swap offer intervention). Participants excluded after the demographics questions were nonDutch (3 participants) or male (93 participants), since only Dutch participants were eligible, and we aimed for 
a representative sample in terms of age and gender. The flow diagram of participant allocation is given in Fig. 2.

\section{Measures \\ Dependent variable}

The dependent variable combined NP score was the summated NP score of the chosen products of each of the four categories (NP scores for each product are given in Additional file 4). The summated NP score ranged from -6 to +58 . The lower the score, the better the product healthfulness.

\section{Mediators}

Ease of identifying the healthy food option was measured by asking how easy it was to identify the healthy product during grocery shopping. Answer options were on a 7 -point Likert scale ranging from " $1=$ totally not easy" to " $7=$ totally easy" [51]. Items to measure situational motivation to choose healthily were adopted from Siemsen, Roth, and Balasubramanian [52] and were translated into health-related items. The four items used for "When being presented with the product choices in this particular version of an online store..." were "I had the intention to choose a healthy product," "I was motivated to choose a healthy product," "I really wanted to choose a healthy product," and "I meant to choose a healthy product." Answer options were on a 7-point Likert scale ranging from " $1=$ totally disagree" to " $7=$ totally agree". The mean of these four items was used as an indication for situational motivation to choose healthily $(\alpha=.935)$.

\section{Moderators}

Health interest was measured with four items developed by Pieniak, Verbeke, Olsen, Hansen, and Brunso [53].
For "In general in my daily life..."; these four items were "health is very important to me," "I care a lot about my health," "health means a lot to me," and "I am very concerned about the health-related consequences of what I do." Health interest was measured on a 7-point scale ranging from " $1=$ totally disagree" to " $7=$ totally agree". The mean was used as an indication for health interest ( $\alpha$ $=.921$ ).

\section{Background variables}

There were also contextual factors that could impact the NP score of consumer's product choices. Demographics, age, gender, education, and household composition were measured to control for significant differences between conditions. Furthermore, previous label use and familiarity with the Nutri-Score label could influence food choice because the occurrence of previous label use might influence the effect of nutrition labeling on healthy food choices [54]. Previous label use was tested with the statement "I usually compare labels to select the most nutritious food," rated on a scale ranging from " $1=$ totally disagree" to " $7=$ totally agree" [55], and respondents were asked to rate how familiar they were with NutriScore labeling (" $1=$ totally not familiar" to " $7=$ totally familiar").

Several studies on food swaps investigated acceptability of swap interventions (e.g. [3, 6]). To test the difference in acceptability between swap conditions, i.e., normal swap, swap in combination with Nutri-Score, and/or descriptive norm message, participants in conditions with a swap offer were asked, "You were just offered a healthier food alternative to the food you originally chose. Is this something you would like to have when you do your usual shopping?" [6]. Furthermore, credibility of swap

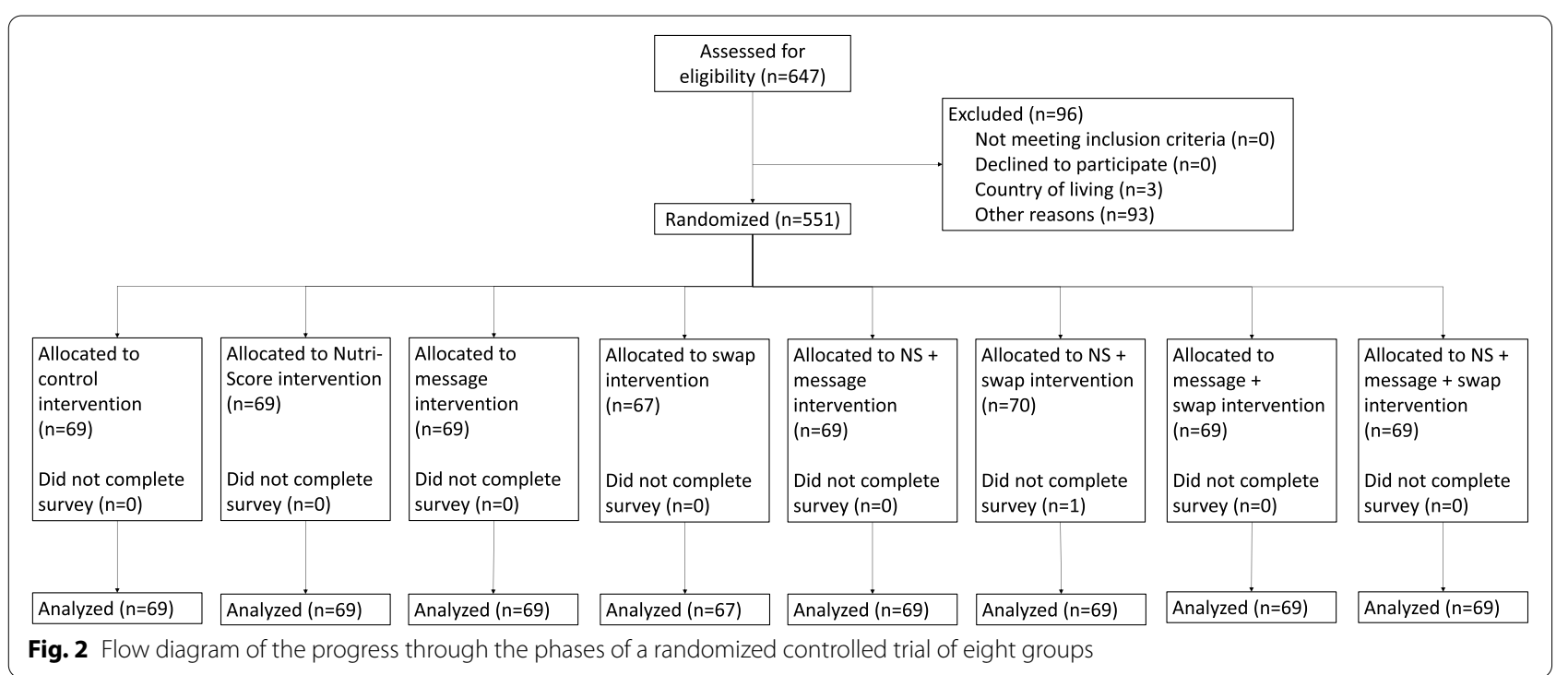


offer(s) was measured with five items by Meyer in [56]: "The alternative product choice that was just offered to me (1) is fair, (2) is unbiased, (3) tells the whole story, (4) is accurate, and (5) is trustworthy." The mean of these five items was used as indication for credibility of swap offer(s) $(\alpha=.886)$. Both acceptability and credibility were measured on a 7 -point scale ranging from " $1=$ totally disagree" to "7 = totally agree".

To control for significant differences between groups, frequency of (online) grocery shopping was measured by asking respondents to indicate how often they shop for groceries in a physical store and online supermarket [57], both before and during COVID-19. These four questions were measured on a 7-point scale ranging from "never" to "daily": (1) never, (2) once a month or less, (3) 2 to 3 times a month, (4) once a week, (5) 2 to 3 times a week, (6) 4 to 5 times a week, or (7) daily. Moreover, to measure whether the simulated online supermarket was perceived as a realistic online shopping experience (credibility of online shopping environment), respondents received the question, "In your opinion, how realistic was the online shopping experience?" They were asked to rate this question on a scale ranging from " $1=$ totally not realistic" to "7 = totally realistic".

\section{Awareness check}

Participants were asked whether they had seen 1) a Nutri-Score label, 2) an additional informative message about the product choice of other Dutch consumers, and 3) an alternative product suggestion for a healthier product option after making a product choice. Answer options included "yes", "no", and "I do not know".

\section{Procedure}

After providing informed consent, participants were shown questions to screen for age (older than 18), gender, and country of residence (the Netherlands). After that, eligible participants were shown the following message:

"Imagine you are at home, figuring out if you still have enough groceries in stock. You find out you need to buy a product from each of the following categories: breakfast cereals, crackers, muesli bars, and pizza. You decide to order these products online."

After reading this scenario, respondents were randomly assigned to one of eight study conditions. Randomization was on a 1:1:1:1:1:1:1:1 basis, using computerized random number generation. Intervention allocation was concealed from researchers until after completion of the experiment, as participants were automatically randomized without human involvement. For each condition, four separate questions were shown with the text
("Imagine you need to buy [breakfast cereals, crackers, muesli bars, pizza] in an online supermarket. Which product would you choose?"), and the different product options were shown. Participants could choose one product for each question. After that, questions regarding mediators, moderators, and background variables were asked.

\section{Statistical analysis}

Randomization of conditions was checked in terms of demographics and background variables between conditions. An overview of the different conditions is given in Table 1. Descriptive analyses were performed. To assess whether there were significant differences between conditions for age, health interest, previous label use, NutriScore familiarity, and credibility of the online shopping environment, a one-way ANOVA was conducted. Pearson Chi Square was used to test for differences in gender, education, household composition, and grocery shopping frequency across conditions. Except for Nutri-Score familiarity, there were no significant differences in demographics and background variables across conditions.

The awareness check tested whether participants in the treatment conditions had noticed the interventions. For each intervention, the frequencies for "yes", "no", and "I do not know" were obtained. To analyze the differences in combined NP score across conditions, a one-way ANOVA with Tukey post hoc was conducted for NP values for products combined across conditions. As Levene's test was highly significant ( $p$-values $<.01$ ), equal variances could not be assumed. Consequently, Games-Howell post hoc tests and Welch ANOVA test were used to test for hypotheses significance. Then, a 3-way ANOVA with Nutri-Score, swap offer and norm message as independent variables was performed to test the direct and interaction effects of the three interventions on the combined NP score (H1).

To explore the mediating effect of ease of identifying the healthy food option and situational motivation to choose healthily between the three interventions and the dependent variable combined NP score, while also taking into account the moderating effect of health interest and situational motivation, PROCESS by Hayes [58] was used. PROCESS Model 21 was used to explore the effect of Nutri-Score and swap offer on the combined NP score via the ease of identifying the healthy food option ( $\mathrm{H} 2 /$ $\mathrm{H} 4 / \mathrm{H} 8$ ), while also testing for moderators health interest (H10) and situational motivation (H9) (moderated moderated mediation). To explore the effect of Nutri-Score labeling and swap offer on the combined NP score via situational motivation to choose healthily $(\mathrm{H} 3 / \mathrm{H} 5 / \mathrm{H} 7)$, while also considering the moderating effect of health interest (H11), PROCESS Model 7 was used (moderated mediation). All data was analyzed using IBM SPSS Statistics 24 with a significance level of $p<.05$. 
Jansen et al. Int J Behav Nutr Phys Act ～（2021) 18:156

Page 7 of 16

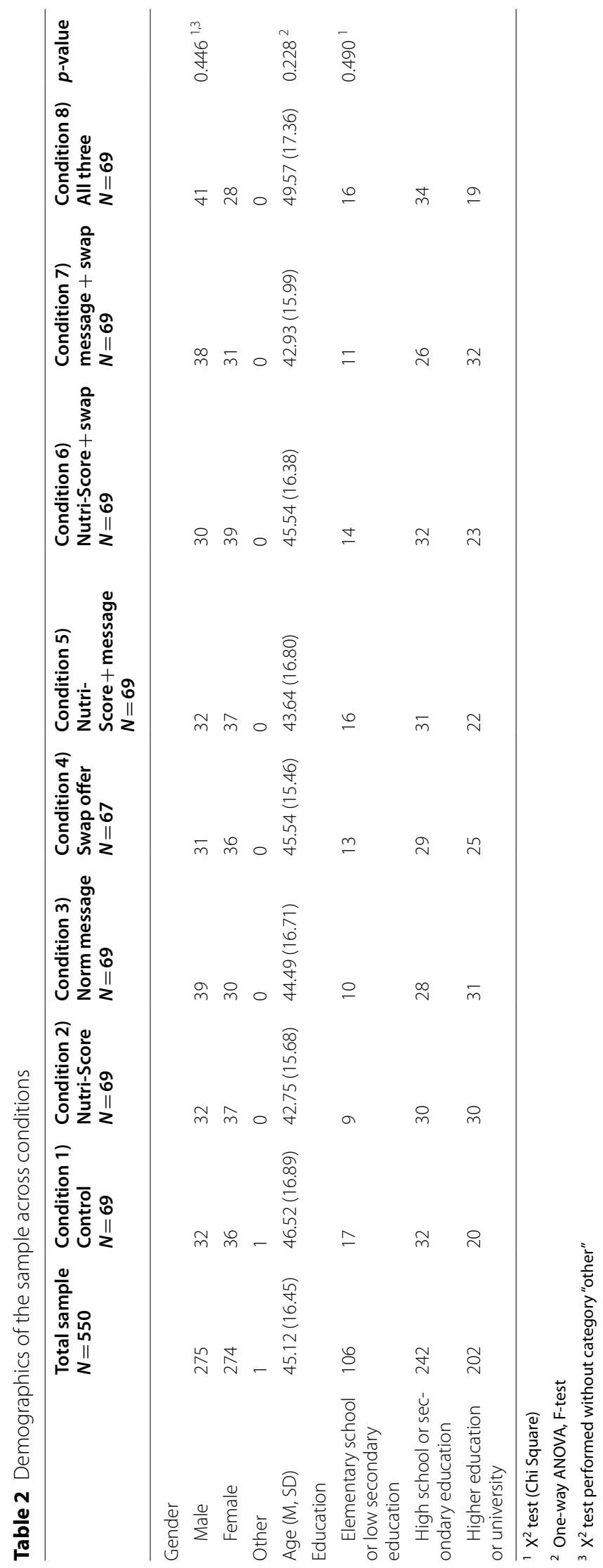




\section{Results}

\section{Descriptives and randomization check}

This research was conducted among 550 participants divided over eight conditions (see Table 2). Gender was equally balanced across conditions, and the average age was $45.12(\mathrm{SD}=16.45)$. All 550 participants lived in the Netherlands. An overview of the sociodemographic characteristics age, gender, and education is given in Table 2, and an overview for household composition and frequency of (online) grocery shopping across conditions is shown in Additional file 7.

\section{Randomization and awareness checks}

Randomization checks There were no differences across the eight conditions at a $5 \%$ significance level in gender $\left(\mathrm{X}^{2}(7)=6.839, p=.45\right)$, age $(\mathrm{F}(7,542)=1.28, p=.26)$ and educational level $\left(\mathrm{X}^{2}(14)=13.464, p=.49\right)$, as shown in Table 2. Also, no significant differences were found for household composition $\left(\mathrm{X}^{2}(21)=23.244, p=.33\right)$, physical grocery shopping frequency before $\left(X^{2}(28)=34.424\right.$, $p=.19)$ and during COVID-19 $\left(\mathrm{X}^{2} \quad(21)=17.633\right.$, $p=.67)$, online grocery shopping frequency before $\left(\mathrm{X}^{2}(14)=10.567, p=.72\right)$ and during COVID-19 $\left(\mathrm{X}^{2}\right.$ $(14)=11.301, p=.66)$, previous label use $(\mathrm{F}(2,542)=1.39$, $p=.21)$, and average health interest $(\mathrm{F}(7,542)=0.37$, $p=.97$ ) (Additional file 7). This means that randomization was successful. There was a significant difference for Nutri-Score familiarity $(\mathrm{F}(7,542)=2.79, p<.01)$ between the Nutri-Score (condition 2) and swap offer condition (condition 4). Moreover, respondents in the conditions with a swap offer were asked about their swap acceptability and perceived credibility. As for swap acceptability, $54 \%$ of the respondents who received a swap somewhat to fully agreed with wanting to receive a swap offer during usual online grocery shopping, and there were no significant differences across the four conditions with a swap $(\mathrm{F}(3,255)=.09, p=.97)$. More than half of the respondents wanted a swap offer, but credibility of the current studies' swaps had a mean value of only $4.53(\mathrm{SD}=1.11)$. Most respondents $(41.5 \%)$ were neutral about the swap credibility, and there were no significant differences across the four swap conditions $(\mathrm{F}(3,254)=.79, p=.50)$.

Awareness checks To check whether participants noticed interventions, a crosstabulation with Chi Square was performed (Table 3). A cross-tabulation with swap offer $\left(\mathrm{X}^{2}(2, N=550)=51.07, p<.001\right)$, Nutri-Score label $\left(\mathrm{X}^{2}(2, N=550)=128.150, p<.001\right)$, and descriptive norm message $\left(\mathrm{X}^{2}(2, N=550)=20.95, p<.001\right)$ was significant, illustrating that the proportions of the answer options depended on the intervention being present or not.
Table 3 Awareness check for the three interventions (swap offer, Nutri-Score, descriptive message)

\begin{tabular}{|c|c|c|c|c|}
\hline & \multicolumn{3}{|c|}{ Answer options } & \multirow[b]{2}{*}{ Tota } \\
\hline & Yes & No & I do not know & \\
\hline \multicolumn{5}{|l|}{ Noticed swap offer } \\
\hline No swap offer (condition 1, 2, 3, 5) & 64 & 146 & 66 & 276 \\
\hline $\begin{array}{l}\text { With swap offer (condition 4, 6, } \\
7,8 \text { ) }\end{array}$ & 144 & 95 & 35 & 274 \\
\hline \multicolumn{5}{|l|}{ Noticed Nutri-Score } \\
\hline No Nutri-Score (condition 1, 3, 4, 7) & 64 & 132 & 48 & 274 \\
\hline $\begin{array}{l}\text { With Nutri-Score (condition 2, 5, } \\
6,8)\end{array}$ & 196 & 53 & 27 & 276 \\
\hline \multicolumn{5}{|l|}{ Noticed social norm message } \\
\hline No message (condition 1, 2, 4, 6) & 66 & 154 & 54 & 274 \\
\hline With message (condition $3,5,7,8$ ) & 116 & 111 & 49 & 276 \\
\hline
\end{tabular}

Note. All $p$-values for $\mathrm{X}^{2}$ test are $<0.001$

\section{Dependent variable and mediators}

Table 4 shows means and standard deviations for the dependent variable and the mediators for the total sample and across conditions involving all participants who were randomly assigned. Half of the respondents (50.73\%) found it easy to identify healthy food options. Ease of identifying the healthy food option was lowest in the swap condition $(M=3.72, \mathrm{SD}=1.69)$, while the highest mean score was found for the condition with all three interventions $(\mathrm{M}=5.06, \mathrm{SD}=1.57)$. These differences were significant as determined by a one-way ANOVA, $\mathrm{F}(7,542)=5.87, p<.001$. Results showed that situational motivation to choose healthily was present for most respondents, and there were no significant differences across conditions $(\mathrm{F}(7,542)=.89, p=.52)$.

A one-way ANOVA was conducted to compare combined NP score across conditions (Table 4). Results showed statistically significant differences in the combined NP score $(\mathrm{F}(7,542)=9.86, p<.001)$. Diving deeper into the effect of conditions on the combined score (Fig. 3) with a highly significant Levene's test statistic $(\mathrm{F}(7,542)=3.04, p<.01)$, Welch's ANOVA test revealed that the eight conditions significantly differed in combined NP score, F(7, 232.017) $=10.82, p<.001$. The Games-Howell post hoc test showed a statistically significant difference only between certain conditions (see Fig. 3).

\section{Hypotheses testing Effect of interventions on combined NP score (hypothesis 1)}

To test the primary hypothesis, a 3-way ANOVA was performed with interventions as independent variables and combined NP score as dependent variable (H1). 


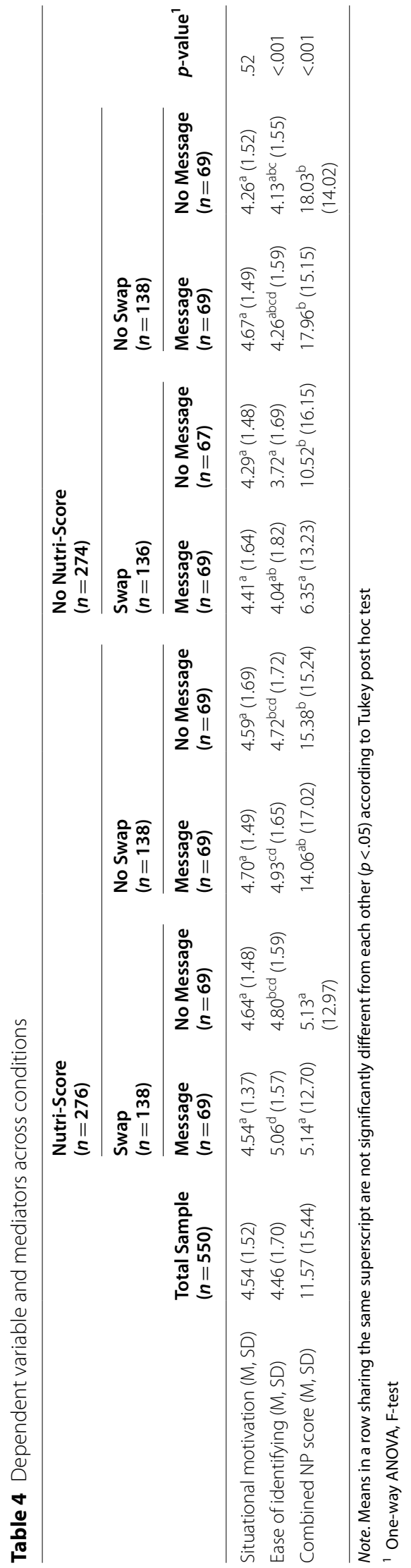




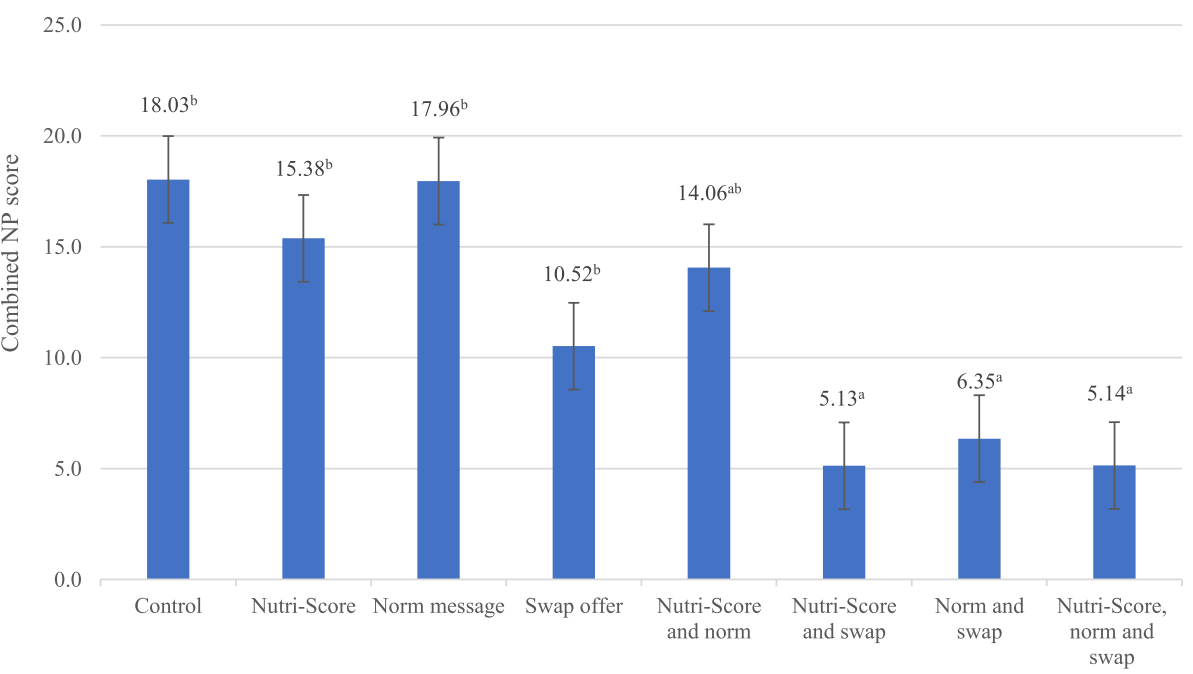

Fig. 3 Mean values and SE of the combined NP score for each condition. Note. Means sharing the same superscript are not significantly different from each other $(p<.05)$ according to Games-Howell post hoc test

Simple main effects showed that combined NP score was indeed significantly influenced by Nutri-Score labeling $(\mathrm{F}(1,542)=6.93, p<.01)$ and swap offer $(\mathrm{F}(1,542)=58.74$, $p<.001)$, while the effect of norm message was not significant $(\mathrm{F}(1,542)=1.24, p=.27)$. No statistically significant 2-way and 3-way interaction were found, as shown with F-test statistics in Table 5. Therefore, parameter estimate results were calculated with only the direct effect of interventions on the dependent variable and showed

Table 52 (Nutri-Score) $\times 2$ (norm message) $\times 2$ (swap offer) ANOVA with combined NP score as dependent variable

\begin{tabular}{lllll}
\hline Factor & df & F & $\boldsymbol{p}$ & $\mathrm{N}^{2}$ \\
\hline Nutri-Score & 1 & 6.929 & .009 & .013 \\
Norm message & 1 & 1.236 & .267 & .002 \\
Swap offer & 1 & 58.743 & .000 & .098 \\
Nutri-score*Norm message & 1 & .347 & .556 & .001 \\
Nutri-Score*Swap offer & 1 & .000 & .993 & .000 \\
Norm message*Swap offer & 1 & .307 & .580 & .001 \\
Nutri-Score*Norm message*Swap offer & 1 & 1.185 & .277 & .002 \\
df $_{\text {ERROR }}$ & 542 & & & \\
\hline
\end{tabular}

that presenting a Nutri-Score label and offering a swap decreased the combined NP score with $3.276(p<.001)$ and $9.579(p<.001)$, respectively (Table 6).

\section{Mediation and moderation analysis}

In addition to the primary analysis, the underlying process was explored with ease of identifying the healthy food options and situational motivation to choose healthily as mediators and health interest as moderator.

Direct effect of interventions on combined NP score (H1) The direct effect of both swap offer and NutriScore on combined NP score were significant with both ease of identification $(b=-10.01, p<.001$ and $\mathrm{b}=-2.60, p=.04$ respectively) and situational motivation $(\mathrm{b}=-9.89, p<.001$ and $\mathrm{b}=-2.62, p=.03$ respectively) as mediators.

Swap offer on ease of identification (H2) and situational motivation (H3) Mediation analysis did not find evidence of a significant effect of swap offer on the ease of

Table 6 Regression parameter estimates results: direct effect of interventions on the combined NP score

\begin{tabular}{|c|c|c|c|c|c|c|}
\hline \multirow[t]{2}{*}{ Factor } & \multirow[t]{2}{*}{ Estimate } & \multirow[t]{2}{*}{ SE } & \multirow[t]{2}{*}{$p$} & \multicolumn{2}{|l|}{$\mathrm{Cl}$} & \multirow[t]{2}{*}{$\mathrm{N}^{2}$} \\
\hline & & & & LB & UB & \\
\hline Intercept & 18.682 & 1.25 & .000 & 16.234 & 21.129 & .292 \\
\hline Nutri-Score & -3.276 & 1.25 & .009 & -5.724 & -.829 & .013 \\
\hline Norm message & -1.378 & 1.25 & .269 & -3.825 & 1.070 & .002 \\
\hline Swap offer & -9.579 & 1.25 & .000 & -12.026 & -7.132 & .098 \\
\hline
\end{tabular}


identifying the healthy food option ( $b=0.69, p=.28)$, nor on the situational motivation to choose healthily $(b=.44$, $p=.38)$.

Nutri-score on ease of identification (H4) and situational motivation (H5) We found no evidence of an effect between Nutri-Score and ease of identifying the healthy food option $(b=-.40, p=.52)$ as well as between NutriScore and situational motivation to choose healthily $(b=-.19, p=.71)$.

Situational motivation on combined NP score (H7) The effect of situational motivation on combined NP score was tested with both swap offer and Nutri-Score as independent variable. The effect was significant for both swap offer $(\mathrm{b}=-3.40, p<.001)$ and Nutri-Score $(b=-3.25$, $p<.001)$.

Ease of identification on combined NP score (H8) The ease of identifying the healthy food option on NP score was non-significant for both swap offer $(b=.88, p=.37)$ and Nutri-Score $(b=.50, p=.63)$.

Effect of situational motivation to choose healthily on association between ease of identification and combined NP score (H9) With swap offer as independent variable, situational motivation did not significantly moderate the relationship between ease of identifying the healthy food option and combined NP score $(b=-.24, p=.21)$, and for the moderating effect, no evidence was found of a significant effect when Nutri-Score was the independent variable $(b=-.10, p=.62)$.

Effect of moderator health interest on association between interventions and ease of identifying the healthy food option (H1Oa and H1Ob) With regard to moderator health interest (H10), a significant effect was found for the moderating effect on the relationship between NutriScore and ease of identifying the healthy food option $(\mathrm{b}=.23, p=.04)(\mathrm{H} 10 \mathrm{~b})$. No evidence was found for a significant effect with a swap offer as intervention $(b=-.16$, $p=.19)(\mathrm{H} 10 \mathrm{a})$.

Effect of moderator health interest on association between interventions and situational motivation (H11a and H11b) When testing the effect of the moderator health interest on the effect between interventions and situational motivation, no evidence was found for a significant relationship between swap offer and situational motivation as proposed in hypothesis $11 \mathrm{a}(b=-.12, p=.22)$. Also, no evidence for the effect proposed in hypothesis $11 \mathrm{~b}$ of the moderator health interest on the relationship between Nutri-Score and situational motivation was found $(b=.07, p=.44)$.

Total effects PROCESS Model 21 was also used to test the moderated moderated mediation effect of the model, which quantifies the indirect effect of swap offer (IV1) or Nutri-Score (IV2) on combined NP score (DV) through ease of identification $(\mathrm{M})$ while taking into account the moderating effect of both health interest and situational motivation. No evidence for a significant effect was found for swap offer (Index $=.0382$, bootstrapped 95\% CI: -.0384 to.1484) or for Nutri-Score (Index $=-.0240$, bootstrapped $95 \% \mathrm{CI}$ : -.1543 to.0778). As for the moderated mediation effect tested with PROCESS Model 7, which quantifies the effect of health interest (moderator) on the indirect effect of Nutri-Score labeling (IV) on combined NP score (DV) through situational motivation (M), we found no evidence for significant relationships. (Index $=-.2380$, bootstrapped 95\% CI: -.9127 to.4143). Full results of primary and explorative analyses are provided in Fig. 4.

\section{General discussion \\ General discussion}

There are many types of interventions that can shape consumer decision-making in the online grocery shopping environment. Online grocery shopping environments can offer novel and more efficient ways for stimulating healthy food choices. The present study examined the effect of swap offers. Nutri-Score labeling, and a norm message on the NP score of food choices in an online grocery store environment. Additionally, we explored whether the effect of the interventions on the combined NP score of food choices is mediated by ease of identification and situational motivation to choose healthily, while also exploring the moderating effect of health interest. In our simulated online grocery shopping environment, participants were asked to choose a product from an assortment of six types of breakfast cereals, crackers, muesli bars, and pizzas.

Current results on the primary analysis provided evidence that Nutri-Score labeling and offering an alternative healthier product with a food swap can be used to guide people toward healthier food choices. Nonetheless, results did not provide any evidence that interventions have a synergistic effect on the NP score when combined. Findings of the current study confirmed that Nutri-Score labeling and swap offers lead to a better combined NP score, which is in line with previous findings (e.g. [4, 20, 59]). Compared to the control condition, the combined NP score decreased by $16.6 \%$ (from 18.03 to 15.38 ) when 


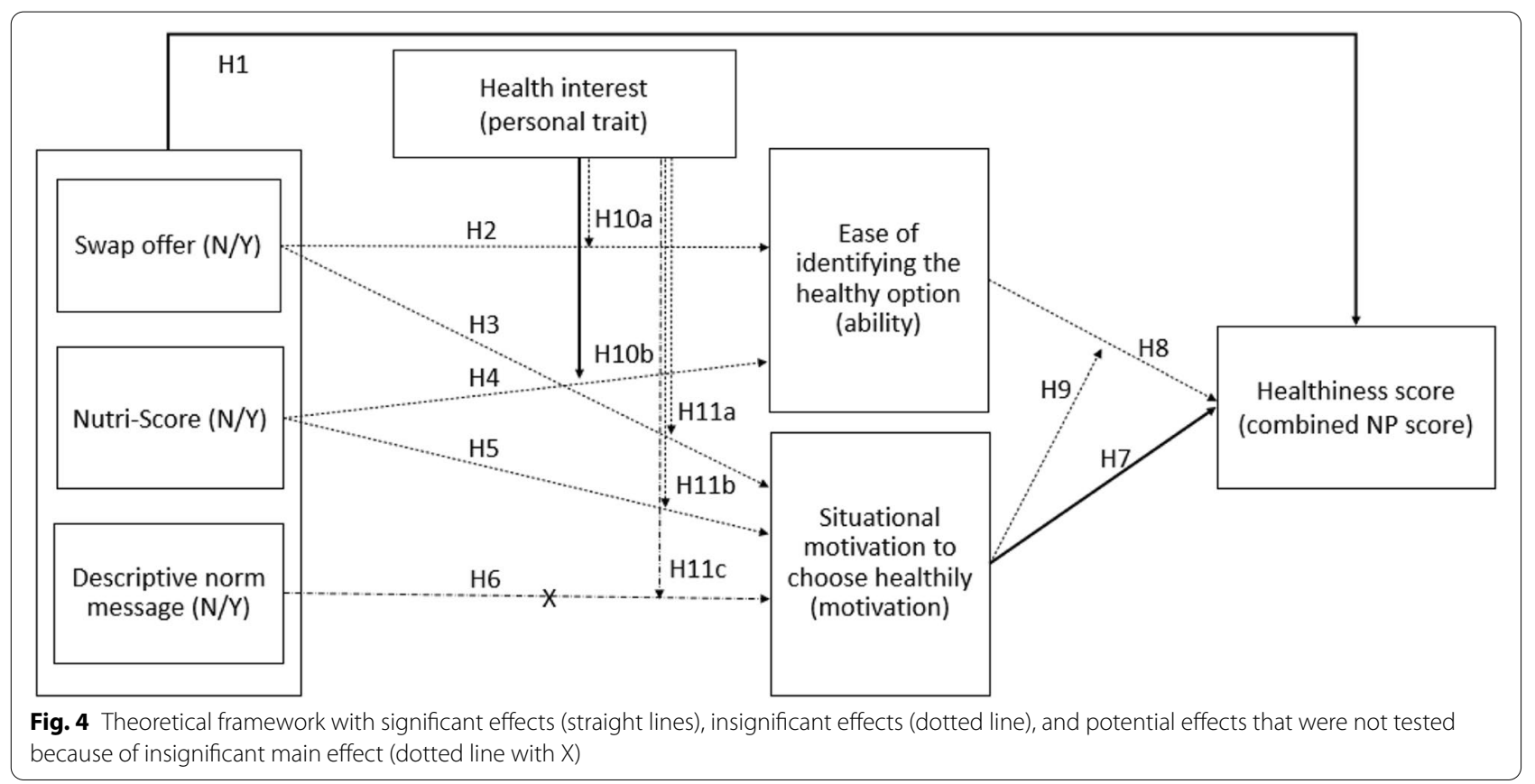

a Nutri-Score label was displayed and by $41.7 \%$ (from 18.03 to 10.52 ) when consumers were offered an alternative product option. A positive effect of Nutri-Score [1820, 28] and swap offers [7-9] on the NP score of chosen products is in line with several other studies.

However, norm messages did not impact participants' food choices. This finding contradicts a common finding of behavioral research (e.g., [60]) but may be explained by the notion that a descriptive norm message effect is greater when the behavior is public versus private [61]. Additionally, the norm message did not specifically guide consumers to a healthier option, so it might have been difficult for consumers to detect the healthiest food option when only a norm message was provided. Also, the norm message was noticed by less than half of the participants in norm message conditions, which could have affected results. Future studies could use a more salient norm message to test its effect on NP score. For the swap offer, around one-third of the respondents in swap conditions could not confirm or were unsure about having received a swap offer, and the same was true for around a quarter of Nutri-Score condition respondents. This could be because respondents forgot or were unaware of the swap or because the survey question used in the awareness check was not well understood. Future research could explore how such interventions are processed by consumers.

With regard to the processes behind the effect of interventions, our exploratory results showed that, contrary to expectations, interventions did not make healthier options easier to identify. This might be because our interventions were unfamiliar to the participants or did not draw sufficient attention to change purchase behavior [62]. Recent studies (e.g., [19, 20]) suggested that Nutri-Score can increase consumers' ability to better understand the nutritional value of products, and therefore identifying which food is healthier becomes easier. Potential reasons for insignificant effects in this study are that respondents did not understand or believe the Nutri-Score label, as 236 (42.91\%) respondents were not familiar with this label, or that no additional nutrition information about the product was given. The need for additional information alongside a Nutri-Score label was shown by Julia et al. [22], who showed that Nutri-Score labels are only effective when combined with an educational leaflet.

Participants who got the swap recommendation were specifically told 'this product is healthier' to make the healthfulness of the selected and recommended product fully transparent, which indeed led to healthier food choices. However, this explicit text did not make identifying healthy food products easier. A potential reason for insignificant results of this mediating variable might be question ambiguity. Respondents might have thought that they had to rate easiness of identifying the healthier food options without considering the swap offer, instead of including the swap offer. In addition, future research should measure ease of identification with multiple items, instead of a single item. 
Situational motivation to choose healthily also did not mediate the effect between interventions and combined NP score, most likely because extrinsic incentives alone do not increase situational motivation to choose healthily [63, 64]. Extrinsic incentives (i.e., Nutri-Score label or swap offer) often only work if intrinsic motivation to perform a certain behavior is also present [63], so a personal goal should provide a behavioral benchmark to follow extrinsic incentives [64]. Specifically for NutriScore labeling, its effect on combined NP score of food choices might not be increased by situational motivation because knowledge about Nutri-Score label was low. Only about $40 \%$ of participants indicated knowledge of the Nutri-Score label, and therefore this label might not have increased health motivation at the moment of choice. Results may be different once Dutch consumers will become more familiar with Nutri-Score. This can be investigated by conducting research in other countries such as Belgium, where inhabitants are already more familiar with Nutri-Score labeling, or future studies in the Netherlands when the Nutri-Score will have been present longer. Moreover, future research can be conducted to test whether interventions have a long term effect on motivation leading to positive effects in future purchases instead of only in this particular shopping trip. Future studies are also advised to investigate the process more in depth and identify the mediators.

In the current paper, health interest was expected to moderate the relationship between interventions and mediators. This was based on earlier findings that the goal of interventions should be in line with personal goals of eating healthy [44, 45, 65]. Consumers with higher health motivations were not more susceptible to the interventions than consumers with lower health motivation. Health interest only moderated the relationship between Nutri-Score and ease of identification, implying that Nutri-Score labeling worked better to identify healthy food options when consumers were interested in healthy eating.

\section{Limitations and future studies}

Future studies should also address some of the limitations inherent in this study. General limitations are the limited number of products used in the experiment and to what extent the shopping environment was perceived as realistic. Respondents were not actually going to buy groceries, so results are about intentions rather than actual behavior. A field experiment using an actual online supermarket with a broad product range can refine insights on the effectiveness of interventions on actual purchases. Even though we omitted brand and price information from the product packaging, the products might still be recognized by the Dutch participants, which may negatively impact the external validity.

Additionally, familiarity with the Nutri-Score label was higher in some experimental conditions, which may have created a confounding effect in this study. Future studies can also investigate whether the effect of Nutri-Score labeling changes when consumers have been exposed to nutritional labels on the local market and are likely to have a higher awareness. Furthermore, Nutri-Score received some criticism, as it does not (yet) fully align with all local nutritional recommendations in the countries where it is applied, which begs for further investigation on the effect of Nutri-Score [66]. As a result, Nutri-Score's international steering committee is reviewing and proposing changes to further improve the NutriScore algorithm and improve its alignment with the national nutritional and dietary recommendations [17].

Finally, a potential reason for not finding many significant effects for mediating and moderating associations is that we asked participants questions regarding these effects after the experiment of choosing food options (temporal order) or because we did not have enough statistical power to explore these hypotheses. We performed our power analysis for the primary analysis (H1) and explorative hypotheses were tested without any additional power calculation. This means that results for explorative hypotheses might be less conclusive. We encourage future researchers to conduct follow-up experiments that investigate what motivates consumers to select a healthy option which is also easy to identify.

\section{Conclusion and practical implications}

In sum, our results provide evidence that Nutri-Score and swap offers can be used in the online store environment to guide people toward healthier food choices. We did not find evidence that the effects of Nutri-Score and food swaps are mediated through situational motivation to choose healthily and ease of identifying healthy food options. Our results have several practical implications. First, the findings indicate that retailers can use swap offers to help people choose healthier products. Care should be taken that the swap offer is appealing and offers a credible alternative to the first choice of consumers, for example by explaining the health reason behind the swap. Second, results provide evidence that Nutri-Score labeling can guide consumers toward healthier food choices in an online store environment. Thus, retailers could use Nutri-Score labeling in the online store environment to steer consumers. It should be noted that the results indicate the need to increase awareness of Nutri-Score labeling among Dutch consumers. Currently, knowledge of the Nutri-Score label is quite low and therefore communication campaigns 
about the label are advised after introducing the label in the Netherlands in 2021. Moreover, it is important for practitioners to keep in mind that Nutri-Score labeling is most likely to be effective when all products in the online environment are displayed with a NutriScore label [13]. This way, consumers are best able to make healthier food choices. Hence, swap offers and Nutri-Score labeling are promising methods to guide consumers to healthier food choices in the online grocery store.

\section{Supplementary Information}

The online version contains supplementary material available at https://doi. org/10.1186/s12966-021-01222-8.

Additional file 1. CONSORT checklist. Description of data: Additional file 1 is a checklist of information to include when reporting a randomized trial.

Additional file 2. TIDieR checklist. Description of data: Additional file 2 is a checklist for intervention description and replication.

Additional file 3. Overview of the images and products used for each product category. Description of data: This additional file gives an overview of the product images that were used in the survey for each product category. The file consists of four categories: (A) breakfast cereals, (B) Crackers, (C) Muesli bars, and (D) Pizza, each consisting of six products.

Additional file 4. Explanation of calculation Nutri-Score. Description of data: Additional file 4 is a table with the calculation for the NP score and corresponding Nutri-Score label for each product that was used in the survey.

Additional file 5. Examples of product choices with a (1) swap offer, (2) Nutri-Score, or (3) descriptive norm message. Description of data: Additional file 5 shows examples of the survey questions that were displayed for the swap offer (Figure A5.1), Nutri-Score labeling (Figure A5.2), and descriptive norm message condition (Figure A5.3).

Additional file 6. Overview of exposures in each treatment group. Description of data: This additional provides an overview of the exposures in each condition. A table is provided where each condition is separately explained.

Additional file 7. Characteristics of the sample across conditions. Description of data: Additional file 7 provides a table with the characteristics of the sample for each condition. Variables presented are household composition, grocery shopping frequency separately for off-line, and online grocery shopping, as well as before and during COVID-19, previous label use, familiarity Nutri-Score, health interest, credibility swap and acceptability.

\section{Acknowledgements}

The authors would like to acknowledge the professional writing service of Wageningen in'to Languages for proofreading the manuscript.

\section{Authors' contributions}

$E V L$ obtained funding for the research and initiated the research project. $L J$ and EVL were involved in the project conceptualization and conceived the study idea and design. $\amalg J$ performed the statistical analysis and drafted the manuscript. EVL and EvK provided academic supervision and support. All authors contributed to the interpretation of the results, contributed to the manuscript and approved the final manuscript. All authors had full access to all data in the study and take responsibility for data integrity and accuracy of data analysis.

\section{Funding}

The present study received funding from Wageningen School of Social Sciences (WASS) from Wageningen University \& Research and from the Dutch 4TU Federation through the Pride and Prejudice project. The funding providers had no further role in the design of the study, the collection, analysis, and interpretation of data, or in writing the manuscript.

\section{Availability of data and materials}

The data set supporting the conclusions of this article is available in the Zenodo repository, [https://doi.org/10.5281/zenodo.4309693]

\section{Declarations}

Ethics approval and consent to participate

Ethical clearance was provided by the institutional Social Sciences Ethics Committee (SEC). Participants provided informed consent prior to taking part in the study.

\section{Consent for publication}

Consent from the participants was asked at the beginning of the questionnaire. We informed the participants that they would get a random respondent number and that their name would not appear anywhere, so anonymity would be guaranteed. We asked the participants to agree or disagree with the processing of data. If they agreed, they would continue with the survey. When disagreeing, they could not participate in the survey.

\section{Competing interests}

The authors declare no competing interests.

Received: 11 December 2020 Accepted: 27 October 2021

Published online: 04 December 2021

\section{References}

1. Pitts SBJ, Ng SW, Blitstein JL, Gustafson A, Niculescu M. Online grocery shopping: promise and pitfalls for healthier food and beverage purchases. Public Health Nutr. 2018;21:3360-76.

2. Häubl G, Murray KB. Preference construction and persistence in digital marketplaces: the role of electronic recommendation agents. J Consum Psychol. 2003;13:75-91.

3. Riches SP, Aveyard P, Piernas C, Rayner M, Jebb SA. Optimising swaps to reduce the salt content of food purchases in a virtual online supermarket: a randomised controlled trial. Appetite. 2019;133:378-86.

4. Hartmann-Boyce J, Bianchi F, Piernas C, Riches SP, Frie K, Nourse R, et al. Grocery store interventions to change food purchasing behaviors: a systematic review of randomized controlled trials. Am J Clin Nutr. 2018;107:1004-16.

5. Eyles H, McLean R, Neal B, Jiang Y, Doughty RN, McLean R, et al. A saltreduction smartphone app supports lower-salt food purchases for people with cardiovascular disease: findings from the SaltSwitch randomised controlled trial. Eur J Prev Cardiol. 2017;24:1435-44.

6. Forwood SE, Ahern AL, Marteau TM, Jebb SA. Offering within-category food swaps to reduce energy density of food purchases: a study using an experimental online supermarket. Int J Behav Nutr Phys Act. 2015;12:1-10.

7. Huang A, Barzi F, Huxley R, Denyer G, Rohrlach B, Jayne K, et al. The effects on saturated fat purchases of providing internet shoppers with purchasespecific dietary advice: a randomised trial. PLos Clin Trials. 2006;1:e22.

8. Koutoukidis DA, Jebb SA, Ordóñez-Mena JM, Noreik M, Tsiountsioura M Kennedy S, et al. Prominent positioning and food swaps are effective interventions to reduce the saturated fat content of the shopping basket in an experimental online supermarket: a randomized controlled trial. Int J Behav Nutr Phys Act. 2019;16:50.

9. Winett RA, Moore JF, Wagner JL, Hite LA, Leahy M, Neubauer TE, et al. Altering shoppers' supermarket purchases to fit nutritional guidelines: an interactive information system. J Appl Behav Anal. 1991;24:95-105.

10. Winett RA, Wagner JL, Moore JF, Walker WB, Hite LA, Leahy M, et al. An experimental evaluation of a prototype public access nutrition information system for supermarkets. Health Psychol. 1991;10:75-8.

11. Grüne-YanoffT, Hertwig R. Nudge versus boost: how coherent are policy and theory? Mind Mach. 2016;26:149-83.

12. Ikonen I, Sotgiu F, Aydinli A, Verlegh PW. Consumer effects of front-ofpackage nutrition labeling: an interdisciplinary meta-analysis. J Acad Mark Sci. 2020;48:360-83. 
13. Hagmann D, Siegrist M. Nutri-score, multiple traffic light and incomplete nutrition labelling on food packages: effects on consumers' accuracy in identifying healthier snack options. Food Qual Prefer. 2020;83:103894.

14. Temple NJ. Front-of-package food labels: a narrative review. Appetite. 2020;144:104485.

15. Egnell M, Talati Z, Gombaud M, Galan P, Hercberg S, Pettigrew S, et al. Consumers' responses to front-of-pack nutritionlLabelling: results from a sample from the Netherlands. Nutrients. 2019;11:1817.

16. Santé Publique France. Nutri-Score. 2020. Available from: https://www. santepubliquefrance.fr/determinants-de-sante/nutrition-et-activite-physi que/articles/nutri-score. Assessed 10 Jan 2020.

17. Rijkinstituut voor Volksgezondheid en Milieu. RIVM collaborates at European level on the implementation of the Nutri-Score label. 2021, February 18. Available from: https://www.rivm.nl/en/news/rivm-collaborat es-at-european-level-on-implemention-of-nutri-score-label. Assessed 3 June 2021.

18. Chantal J, Hercberg S, Organization WH. Development of a new front-ofpack nutrition label in France: the five-colour Nutri-score. Public Health Panorama. 2017:3:712-25.

19. Egnell M, Ducrot P, Touvier M, Allès B, Hercberg S, Kesse-Guyot E, et al. Objective understanding of Nutri-score front-of-package nutrition label according to individual characteristics of subjects: comparisons with other format labels. PLoS One. 2018;13:e0202095.

20. De Temmerman J, Heeremans E, Slabbinck H, Vermeir I. The impact of the Nutri-score nutrition label on perceived healthfulness and purchase intentions. Appetite. 2021;157.

21. Dubois $P$, Albuquerque $P$, Allais $\mathrm{O}$, Bonnet $C$, Bertail $\mathrm{P}$, Combris $\mathrm{P}$, et al. Effects of front-of-pack labels on the nutritional quality of supermarket food purchases: evidence from a large-scale randomized controlled trial. J Acad Mark Sci. 2021;49(1):119-38.

22. Julia $C$, Blanchet $O$, Méjean C, Péneau $S$, Ducrot $P$, Allès $B$, et al. Impact of the front-of-pack 5-colour nutrition label (5-CNL) on the nutritional quality of purchases: an experimental study. Int J Behav Nutr Phys Act. 2016:13:1-9.

23. Burger JM, Bell H, Harvey K, Johnson J, Stewart C, Dorian K, et al. Nutritious or delicious? The effect of descriptive norm information on food choice. J Soc Clin Psychol. 2010;29:228-42.

24. Sunstein CR. Nudging: a very short guide. J Consum Policy. 2014:37:583-8.

25. Higgs S. Social norms and their influence on eating behaviours. Appetite. 2015:86:38-44

26. Wright B, Bragge P. Interventions to promote healthy eating choices when dining out: a systematic review of reviews. Br J Health Psychol. 2018;23:278-95

27. Cialdini RB, Goldstein NJ. Social influence: compliance and conformity. Annu Rev Psychol. 2004;55:591-621.

28. Julia C, Hercberg S. Nutri-score: evidence of the effectiveness of the French front-of-pack nutrition label. Ernahrungs Umschau. 2017;64:181-7.

29. Ducrot P, Julia C, Méjean C, Kesse-Guyot E, Touvier M, Fezeu LK, et al. Impact of different front-of-pack nutrition labels on consumer purchasing intentions: a randomized controlled trial. Am J Prev Med. 2016:50:627-36.

30. Egnell M, Galan P, Farpour-Lambert NJ, Talati Z, Pettigrew S, Hercberg S, et al. Compared to other front-of-pack nutrition labels, the Nutri-score emerged as the most efficient to inform Swiss consumers on the nutritional quality of food products. PLoS One. 2020;15:e0228179.

31. Knox B. Consumer perception and understanding of risk from food. Br Med Bull. 2000;56:97-109.

32. Guay F, Vallerand RJ, Blanchard C. On the assessment of situational intrinsic and extrinsic motivation: the situational motivation scale (SIMS). Motiv Emot. 2000;24(3):175-213.

33. Kim J-N, Grunig JE. Problem solving and communicative action: a situational theory of problem solving. J Commun. 2011;61:120-49.

34. Tucker CM, Smith TM, Arthur TM, Wall W. Obesity and related chronic health conditions as predictors of motivation to engage in healthy eating behaviors among black adults. J Racial Ethn Health Disparities. 2014:1:102-9

35. Cialdini RB, Reno RR, Kallgren CA. A focus theory of normative conduct: recycling the concept of norms to reduce littering in public places. J Pers Soc Psychol. 1990;58:1015.
36. Robinson E, Fleming A, Higgs S. Prompting healthier eating: testing the use of health and social norm based messages. Health Psychol. 2014:33:1057.

37. Sharps M, Robinson E. Encouraging children to eat more fruit and vegetables: health vs. descriptive social norm-based messages. Appetite. 2016;100:18-25.

38. Petty RE, Cacioppo JT. Issue involvement can increase or decrease persuasion by enhancing message-relevant cognitive responses. J Pers Soc Psychol. 1979;37:1915.

39. Turner MM, Skubisz C, Pandya SP, Silverman M, Austin LL. Predicting visual attention to nutrition information on food products: the influence of motivation and ability. J Health Commun. 2014;19:1017-29.

40. Baranowski T, Cullen KW, Nicklas T, Thompson D, Baranowski J. Are current health behavioral change models helpful in guiding prevention of weight gain efforts? Obes Res. 2003;11:23S-43S.

41. ThØgersen J. Understanding of consumer behaviour as a prerequisite for environmental protection. J Consum Policy. 1995;18:345-85.

42. Drichoutis AC, Lazaridis P, Nayga RM. Consumers' use of nutritional labels: a review of research studies and issues. Acad Mark Sci Rev. 2006;9:1-22.

43. Hieke $S$, Taylor CR. A critical review of the literature on nutritional labeling. J Consumer Aff. 2012;46:120-56.

44. Maheswaran D, Meyers-Levy J. The influence of message framing and issue involvement. J Mark Res. 1990;27:361-7.

45. Rothman AJ, Salovey P. Shaping perceptions to motivate healthy behavior: the role of message framing. Psychol Bull. 1997;121:3.

46. FoodStandardsAgency. The Nutrient Profiling Model. 2011, January 14. Available from: https://www.gov.uk/government/publications/the-nutri ent-profiling-model. Assessed 29 Feb 2020.

47. Delhaize. Delhaize webshop. 2020. Available from: https://www.delhaize. be/nl-be/. Assessed 20 Apr 2020.

48. RIVM. Voedselconsumptiepeiling. 2019, March 19. Available from: https:// www.rivm.nl/voedselconsumptiepeiling. Assessed 25 Feb 2020.

49. Zandstra EH, Carvalho ÁH, Van Herpen E. Effects of front-of-pack social norm messages on food choice and liking. Food Qual Prefer. 2017;58:85-93.

50. CBS. 2020. Available from: https://opendata.cbs.nl/\#/CBS/nl/. Assessed 07 May 2020.

51. Likert R. A technique for the measurement of attitudes. Arch Psychol. 1932;140:1-55.

52. Siemsen E, Roth AV, Balasubramanian S. How motivation, opportunity, and ability drive knowledge sharing: the constraining-factor model. J Oper Manag. 2008;26:426-45.

53. Pieniak Z, Verbeke W, Olsen SO, Hansen KB, Brunsø K. Health-related attitudes as a basis for segmenting European fish consumers. Food Policy. 2010;35:448-55.

54. Kees J, Royne MB, Cho YN. Regulating front-of-package nutrition information disclosures: a test of industry self-regulation vs. other popular options. J Consum Aff. 2014;48:147-74.

55. Vyth EL, Steenhuis IH, Vlot JA, Wulp A, Hogenes MG, Looije DH, et al. Actual use of a front-of-pack nutrition logo in the supermarket: consumers' motives in food choice. Public Health Nutr. 2010;13:1882-9.

56. Roberts C. Correlations among variables in message and messenger credibility scales. Am Behav Sci. 2010;54:43-56.

57. Goldsmith RE, Horowitz D. Measuring motivations for online opinion seeking. J Interact Advert. 2006;6:2-14.

58. Hayes AF. Introduction to mediation, moderation, and conditional process analysis: A regression-based approach. New York: Guilford publications; 2017.

59. Zou P, Liu J. How nutrition information influences online food sales. J Acad Mark Sci. 2019;47:1132-50.

60. Burger JM, Shelton M. Changing everyday health behaviors through descriptive norm manipulations. Soc Influ. 2011;6:69-77.

61. Melnyk V, van Herpen E, Trijp H. The influence of social norms in consumer decision making: a meta-analysis. ACR North Am Adv. 2010.

62. Bialkova S, van Trijp H. What determines consumer attention to nutrition labels? Food Qual Prefer. 2010;21:1042-51.

63. Cerasoli CP, Nicklin JM, Ford MT. Intrinsic motivation and extrinsic incentives jointly predict performance: a 40-year meta-analysis. Psychol Bull. 2014:140:980

64. Callahan JS, Brownlee AL, Brtek MD, Tosi HL. Examining the unique effects of multiple motivational sources on task performance. J Appl Soc Psychol. 2003:33:2515-35. 
65. Hillhouse J, Turrisi R, Scaglione NM, Cleveland MJ, Baker K, Florence LC. A web-based intervention to reduce indoor tanning motivations in adolescents: a randomized controlled trial. Prev Sci. 2017;18:131-40.

66. Eijsden M, Roost M. Front-f-pack (FOP) voedselkeuzelogo's: hoe te komen tot wél een succesvol logo. 2019. Retrieved from https://voedingsjungle. files.wordpress.com/2019/10/brandbrief_front-of-pack-nutrition-abell ing_voedingsjungle_def-2-1.pdf

\section{Publisher's Note}

Springer Nature remains neutral with regard to jurisdictional claims in published maps and institutional affiliations.

- fast, convenient online submission

- thorough peer review by experienced researchers in your field

- rapid publication on acceptance

- support for research data, including large and complex data types

- gold Open Access which fosters wider collaboration and increased citations

- maximum visibility for your research: over $100 \mathrm{M}$ website views per year

At BMC, research is always in progress.

Learn more biomedcentral.com/submissions 